\title{
A relação família-escola: intersecções e desafios ${ }^{1}$
}

\section{The family-school relationship: convergences and challenges}

\author{
Cynthia Bisinoto Evangelista de OLIVEIRA² \\ Claisy Maria MARINHO-ARAÚJO²
}

\begin{abstract}
Resumo
A partir de revisão de literatura, este trabalho analisa questões referentes à relação família-escola. Apresenta-se a definição de família, suas diferentes composições e sua função específica; abordam-se a especificidade da escola e a interdependência existente entre a família e esse sistema. Exploram-se concepções acerca desta relação, as quais são divididas entre enfoque sociológico e psicológico. Relatos de pesquisas que investigaram esta relação sob o ponto de vista dos diferentes atores envolvidos são apresentados. As reflexões desencadeadas pela revisão bibliográfica apontam uma relação marcada por situações vinculadas a algum problema, pela ação da escola em orientar os pais sobre como educar seus filhos, e pelo decréscimo da participação dos pais nas atividades escolares à medida que o filho avança nas séries. Diante do panorama atual das relações família-escola, tem-se o desafio de realizar novas pesquisas e contribuir para transformar esta relação por meio da valorização dos aspectos positivos relacionados ao processo educativo.
\end{abstract}

Unitermos: Relações pais-escola. Psicologia escolar. Educação.

\begin{abstract}
Based on a study of the literature, this work analyzes questions related to the family-school relationship. It offers a definition of the family, its different compositions and its specific function; it deals with the specifics of school and the existing interdependence between both systems. Concepts concerning this relationship are explored, which are divided into a sociological and a psychological approach. Researches involving the family-school relationship are presented, according to special treatment to the views of the various players involved in the relationship. The reflections from a study of the literature suggest a relationship punctuated by situations with some kind of problem, by the school's actions in teaching the parents about how to be parents and by the decreased participation of parents in school activities as the child progresses through school. Given the present situation with family-school relationships, the challenge is to develop new research and help to transform this relationship through the appreciation of the positive aspects related to the educational process.
\end{abstract}

Uniterms: Parent-school relationship. School psychology. Education.

A temática da relação família-escola tem sido pouco pesquisada no contexto brasileiro pela psicologia e, especialmente, pela psicologia escolar.
Apesar de a família e a escola serem os principais contextos de desenvolvimento humano, poucos estudos científicos têm-se dedicado a compreen-

\section{$\boldsymbol{\nabla} \mathbf{v} \boldsymbol{\nabla}$}

1 Artigo elaborado a partir da dissertação de C.B.E. OLIVEIRA, intitulada "Psicologia escolar e a relação família-escola no ensino médio: estudando as concepções desta relação". Universidade de Brasília, 2007.

2 Universidade de Brasília, Instituto de Psicologia, Departamento de Psicologia Escolar e do Desenvolvimento. Campus Universitário Darcy Ribeiro, 70910-900, Brasília, DF, Brasil. Correspondência para/Correspondence to: C.B.E. OLIVEIRA. E-mail: <cynthia.b@uol.com.br>. 
der de forma sistemática a relação existente entre ambas.

Se, por um lado, a relevância da família e da escola como contextos privilegiados de desenvolvimento humano está bastante consolidada em virtude dos estudos da psicologia da família e da psicologia do desenvolvimento, por outro, os aspectos que constituem e intervêm na relação entre estes dois contextos, sejam como barreiras à colaboração ou contribuindo para a sua promoção, ainda não estão suficientemente estabelecidos. Ocorre, então, que um dos reflexos do baixo desenvolvimento de pesquisas científicas voltadas à inter-secção que se estabelece cotidianamente entre a família e a escola é a ausência de publicações suficientemente atuais nesta temática.

Diante do exposto, este trabalho configura-se como uma oportunidade para ampliar a publicação sobre o tema da relação família-escola no contexto brasileiro, somando-se às já existentes, contempladas neste trabalho.

De forma geral, as pesquisas que têm essa temática como objeto de estudo priorizam a investigação junto a um dos segmentos desta relação, principalmente os pais e os professores. Diferentemente, este trabalho traduz o esforço de reunir e apresentar a opinião dos diferentes atores envolvidos na relação: os pais, os alunos e a escola, representada por seus professores e pelos psicólogos escolares.

Desta forma, a partir do estudo da literatura sobre a relação família-escola, este artigo traz a análise de algumas questões referentes a esta temática, sinalizando pontos que favorecem a compreensão atual desta relação, bem como outros que apontam para a modificação e o sucesso da mesma.

A família é considerada a primeira agência educacional do ser humano e é responsável, principalmente, pela forma com que o sujeito se relaciona com o mundo, a partir de sua localização na estrutura social.

Existem muitas formas de entender o conceito de família, sendo que suas definições tradicionais baseiam-se em diferentes critérios como, por exemplo, restrições jurídicas e legais, aproximações genealógicas, perspectiva biológica de laços sanguíneos e compar100 tilhamento de uma casa com crianças (Petzold, 1996).
De acordo com Trost (1995), a menor unidade de grupo é o casal, uma díade ou um par e, em seu entendimento, uma família se forma quando um casal se casa ou quando passa a viver na mesma casa (coabitação), ou mesmo quando uma criança nasce e é criada por apenas um dos pais solteiros (pai ou mãe). Esta concepção privilegia a díade enquanto unidade mínima da família, que deve ser constituída, pelo menos, por dois adultos ou por um adulto e uma criança. Infere-se, da definição de Trost (1995) acerca da família, que se incluem os casais que se constituíram legalmente, mediante casamento civil e/ou religioso, e também os que apenas optaram por morar juntos, considerando, ainda, os casais heterossexuais e homossexuais.

Buscando estabelecer uma definição de família, Petzold (1996) lembra que o critério de intimidade deve ser a variável fundamental para definir família, o que, consequentemente, reflete-se no fato de que mesmo os casais sem filhos são reconhecidos como uma unidade familiar. A partir desta consideração, a família é um grupo social especial, caracterizado por intimidade e por relações intergeracionais (Petzold, 1996).

Focalizando a realidade brasileira no que concerne à definição de família, a Constituição da República Federativa do Brasil (1988) estabelece os princípios fundamentais em relação à instituição familiar e reconhece como entidade familiar a união estável entre homem e mulher, ou a comunidade formada por quaisquer dois pais e seus descendentes. Nota-se uma diferença significativa na definição estabelecida pela Constituição Brasileira em relação às apresentadas anteriormente quanto à não inclusão das relações não heterossexuais enquanto unidade familiar.

Apesar da crescente discussão acerca das possíveis definições de família e da busca por um conceito comum, ainda não é possível afirmar que exista uma definição de família que seja aceita e adotada consensualmente pelos estudiosos da área, pelas instituições governamentais e pela sociedade. Mesmo não havendo essa concordância unânime acerca da definição de família, há que se privilegiar aquelas definições que contemplam as variáveis mínimas, ou básicas, do que se entende por família, pois é a partir destas variáveis que se poderão realizar estudos e pesquisas mais amplos e representativos das relações humanas. Tais variáveis se referem, neste momento, à existência de 
uma díade e à intimidade vivenciada por seus membros nesta relação.

Em função desta ampliação conceitual sobre família, o termo permite, atualmente, a inclusão de modelos variados de família, para além daquele tradicionalmente conhecido. Os modelos familiares não mais se restringem à família nuclear que compreendia a esposa, o marido e seus filhos biológicos (Turner \&West, 1998). Atualmente há uma diversidade de famílias no que diz respeito à multiplicidade cultural, orientação sexual e composições.

Nesse sentido, os diferentes tipos de família que têm sido descritos com maior frequência pelos pesquisadores da área são: família homossexual ou casais homossexuais; família extensa; famílias multigeracionais; família reconstituída ou recasada; família de mãe ou pai solteiro; casais que coabitam/vivem juntos; viver com alguém cuidando dele (Petzold, 1996; Stratton, 2003; Turner \&West, 1998).

Tendo em vista a diversidade de organizações familiares, considera-se que a referência às famílias diz respeito àquelas configurações familiares compostas por, pelo menos, um adulto e uma criança ou adolescente.

\section{Função social da família, da escola e interdependência dos sistemas família e escola}

Educação e escola têm um relação estreita, apesar de esta não configurar uma relação de dependência, pois há uma distinção entre a educação escolar e a educação que ocorre fora da escola. De acordo com Guzzo (1990), o sentido etimológico da palavra educar significa promover, assegurar o desenvolvimento de capacidades físicas, intelectuais e morais, sendo que, de forma geral, tal tarefa tem sido de responsabilidade dos pais.

De acordo com Bock, Furtado e Teixeira (1999), o grupo familiar tem uma função social determinada a partir das necessidades sociais, sendo que entre suas funções está, principalmente, o dever de garantir o provimento das crianças para que possam exercer futuramente atividades produtivas, bem como o dever de educá-las para que "tenham uma moral e valores compatíveis com a cultura em que vivem" (p.238). Nesse mesmo sentido, Oliveira (2002) resume a função da família dizendo que "a educação moral, ou seja, a trasmissão de costumes e valores de determinada época torna-se, nesta perspectiva, seu principal objetivo" (p.16).

A responsabilidade familiar junto às crianças em termos de modelo que a criança terá e do desempenho de seus papéis sociais é tradicionalmente chamada de educação primária, uma vez que tem como tarefa principal orientar o desenvolvimento e aquisição de comportamentos considerados adequados, em termos dos padrões sociais vigentes em determinada cultura.

A escola é a instituição que tem como função a socialização do saber sistematizado, ou seja, do conhecimento elaborado e da cultura erudita. De acordo com Saviani (2005), a escola se relaciona com a ciência e não com o senso comum, e existe para proporcionar a aquisição de instrumentos que possibilitam o acesso ao saber elaborado (ciência) e aos rudimentos (bases) desse saber. A contribuição da escola para o desenvolvimento do sujeito é específica à aquisição do saber culturalmente organizado e às áreas distintas de conhecimento. No que diz respeito à família, "um dos seus papéis principais é a socialização da criança, isto é, sua inclusão no mundo cultural mediante o ensino da língua materna, dos símbolos e regras de convivência em grupo, englobando a educação geral e parte da formal, em colaboração com a escola" (Polonia \& Dessen, 2005, p.304).

Escola e família têm suas especificidades e suas complementariedades. Embora não se possa supô-las como instituições completamente independentes, não se pode perder de vista suas fronteiras institucionais, ou seja, o domínio do objeto que as sustenta como instituições.

Esses dois sistemas têm objetivos distintos, mas que se interpenetram, uma vez que "compartilham a tarefa de preparar as crianças e os jovens para a inserção crítica, participativa e produtiva na sociedade" (Reali \& Tancredi, 2005, p.240). A divergência entre escola e família está na tarefa de ensinar, sendo que a primeira tem a função de favorecer a aprendizagem dos conhecimentos construídos socialmente em determinado momento histórico, de ampliar as possibilidades de convivência social e, ainda, de legitimar uma ordem social, enquanto a segunda tem a tarefa de promover a socialização das crianças, incluindo o aprendizado de padrões comportamentais, atitudes e valores aceitos pela sociedade. 
Desta forma entende-se que, apesar de escola e família serem agências socializadoras distintas, as mesmas apresentam aspectos comuns e divergentes: compartilham a tarefa de preparar os sujeitos para a vida socioeconômica e cultural, mas divergem nos objetivos que têm nas tarefas de ensinar.

\section{Relação família-escola}

Tendo como pano de fundo a divisão de responsabilidades no que concerne à educação e socialização de crianças e jovens e a relação que se estabelece entre as instituições familiares e escolares, pesquisas e levantamentos acerca desta relação passam a ser objeto de estudo de diversas áreas do conhecimento, como a psicologia, a sociologia, a educação, entre outras.

Considerando as várias perspectivas e abordagens relativas ao tema, os trabalhos e pesquisas sobre a temática da relação família-escola podem ser organizados em dois grandes grupos, denominados enfoque sociológico e enfoque psicológico (Oliveira, 2002).

No enfoque sociológico a relação família-escola é vista em função de determinantes ambientais e culturais. A relação entre educação e classe social mostra um certo conflito entre as finalidades socializadoras da escola (valores coletivos) e a educação doméstica (valores individuais), ou seja, entre a organização da família e os objetivos da escola. As famílias que não se enquadram no suposto modelo desejado pela escola são consideradas as grandes responsáveis pelas disparidades escolares. Seguindo este enfoque, faz-se necessário, para o bom funcionamento da escola, que as famílias adotem as mesmas estratégias de socilização por elas utilizadas.

Assim, a representação de modelo familiar certo/correto ganha projeção e se naturaliza, tendo a própria escola como disseminadora da ideia de que algumas famílias operam de modo diverso do seu objetivo. Em função dessa divergência, as estratégias de socilização das famílias passam a ser a preocupação da escola, de forma que esta amplia seus âmbitos de ação, tentando assumir ou tentando substituir a família em sua ampla missão socializadora. Para Oliveira (2002), há uma intenção que passa muitas vezes despercebida nessa tentativa de aproximação e colaboração, que é a "desestruturadas". O ambiente escolar exerce um poder de orientação sobre os pais para que estes possam educar melhor os filhos e estes, por sua vez, possam frequentar a escola.

Enquanto no enfoque sociológico a família é responsabilizada pela formação social e moral do indivíduo, no enfoque psicológico ela é responsabilizada pela formação psicológica. A ideia de que a família é a referência de vida da criança - o locus afetivo e condição sine qua non de seu desenvolvimento posterior - será utilizada para manter certa ligação entre o rendimento escolar do aluno e sua dinâmica familiar, colocando, mais uma vez, a família no lugar de desqualificada (Oliveira, 2002).

Nesse enfoque, as razões de ordem emocional e afetiva ganham um colorido permanente quanto ao entendimento da relação família-escola e da ocorrência do fracasso escolar. Ganha status natural a crença de que uma "boa" dinâmica familiar é responsável pelo "bom" desempenho do aluno. As descrições centradas no plano afetivo ganham a atenção dos professores que, com algum conhecimento de psicologia, levam esse discurso para dentro da sala de aula e passam, em um processo naturalizado por todos, a avaliar e analisar o comportamento dos alunos.

Posto desta forma, nota-se que o enfoque sociológico aborda os determinantes ambientais e culturais presentes na relação família-escola, destacando que cabe à escola cumprir as exigências sociais, enquanto o enfoque psicológico considera os determinantes psicológicos presentes na estrutura familiar como os grandes responsáveis pelo desencontro entre objetivos e valores nas duas instituições. Assim, em uma espécie de complementaridade, encontra-se um velado enfrentamento da escola com a família, aparentemente diluído nos grandes projetos de participação e de parceria entre esses dois sistemas, podendo-se afirmar que em ambos os enfoques destacam-se dois aspectos principais: 1) a incapacidade da família para a tarefa de educar os filhos e 2) a entrada da escola para subsidiar essa tarefa, principalmente quando se trata do campo moral (Oliveira, 2002).

A partir destas colocações, vê-se que a relação família-escola está permeada por um movimento de culpabilização e não de responsabilização compartilhada, além de estar marcada pela existência de uma 
forte atenção da escola dirigida à instrumentalização dos pais para a ação educacional, por se acreditar que a participação da família é condição necessária para o sucesso escolar (Oliveira, 2002).

\section{A quem caberia a responsabilidade de construir essa relação?}

No relato de muitos professores há a afirmação de que, apesar de abrirem as portas da escola à participação dos pais, esses são desinteressados em relação à educação dos filhos, na medida em que atribuem à escola toda a responsabilidade pela educação. Esta argumentação dos professores "visa, apenas, culpar a vítima e é uma visão pessimista das relações escola/pais" (Marques, 1999, p.15), a partir da qual não se consegue dar passos positivos para ultrapassar os obstáculos à relação família-escola.

Ao contrário dos professores que acreditam que os pais é que devem ir à escola mostrando-se interessados pelo desenvolvimento de seus filhos e pela relação entre família e escola, Tancredi e Reali (2001), Reali e Tancredi (2002), Caetano (2004) acreditam que a construção da parceria entre escola e família é função inicial dos professores, pois eles são elementos-chave no processo de aprendizagem. Dada a formação profissional específica que têm, as tentativas de aproximação e de melhoria das relações estabelecidas com as famílias devem partir, preferencialmente, da escola, pois "transferir essa função à família somente reforça sentimentos de ansiedade, vergonha e incapacidade aos pais, uma vez que não são eles os especialistas em educação" (Caetano, 2004, p. 58).

Todavia, apesar desse discurso em que se fala que a escola é que deve ir às famílias, os modelos de envolvimento entre as famílias e a escola focalizam principalmente os pais e se referem pouco às ações dos professores e da escola na promoção da relação família-escola, como mostram os modelos propostos por Joyce Epstein, Don Davies e Owen Heleen (Marques, 1999).

Para exemplificar, o modelo de Joyce Epstein (Marques, 1999) defende a existência de cinco tipos de envolvimento: a) os pais ajudarem os filhos em casa, que diz respeito à função dos pais em atender as necessidades básicas dos filhos e em organizar a rotina familiar diária; b) os professores comunicarem-se com os pais, que se refere à função da escola de informar os pais acerca do regulamento interno da escola, dos programas escolares e dos progressos e dificuldades dos filhos; c) envolvimento dos pais na escola, apoiando voluntariamente a organização de festas e alunos com dificuldades de aprendizagem; d) envolvimento dos pais em atividades de aprendizagem, em casa, participando da realização de trabalhos, projetos e deveres de casa; e) envolvimento dos pais na direção das escolas, influenciando e participando da tomada de decisões, se possível.

$\mathrm{O}$ aspecto mais comum entre os três modelos (Joyce Epstein, Don Davies e Owen Heleen) refere-se ao fato de que em todos a ação dos pais é priorizada, seja diante de questões pedagógicas (ensino tutorial em casa ou na escola, trabalho voluntário dos pais na escola e na sala de aula, apoio na realização de tarefas, trabalhos e atividades de aprendizagem) ou de questões políticas (pais com poder deliberativo na escola, participando e influenciando a tomada de decisões). Os modelos pouco se referem às ações da escola e dos professores no sentido de promover a relação família-escola; tais ações são referidas somente nas ocasiões em que cabe à escola informar aos pais acerca do regulamento interno da escola, dos programas escolares e de progressos e dificuldades dos filhos.

Ao listar as "16 maneiras de envolver os pais na escola", Marques (1999) fez uma adaptação do trabalho de Joyce Epstein e elaborou uma lista de procedimentos que podem favorecer a aproximação das famílias. Entretanto, tal lista menciona, exclusivamente, ações a serem desencadeadas pelos pais no contexto familiar, sem haver menção à interação família-escola.

Além de tais ações se referirem apenas a atitudes a serem adotadas pelos pais, fica explícita, entre as maneiras listadas, a crença existente acerca da necessidade de orientar e ensinar aos pais sobre como ensinar seus filhos: "explicar aos pais certas técnicas de ensino" ou "propor aos pais que treinem os filhos, ajudando-os a fazer exercícios de leitura, matemática, etc." (Marques, 1999, p. 21).

Tais atitudes decorrem da noção da escola de que o envolvimento dos pais aparece relacionado à participação e colaboração nas atividades propostas pela escola e no interesse pelo desempenho de seus filhos. As expectativas quanto à participação dos pais 
envolvem o acompanhamento da tarefa de casa ou a formação do aluno em termos de disciplina, respeito e comportamento adequado (Hernández, 1995).

Junto a diretores e professores percebe-se, também, a pouca tendência da escola para buscar uma parceria. É interessante observar a colocação acerca do posicionamento contraditório dos diretores e professores que, por um lado,"acusaram os pais de falta de compreensão ou aceitação dos problemas das crianças, e o pouco retorno de seus esforços para ajudá-los" (Hernández, 1995, p.107), mas, por outro lado, sentem-se invadidos pela presença dos pais, pois consideram que os pais não sabem participar com uma relação de colaboração, mas sim de cobrança, uma vez que não entendem do processo de ensino-aprendizagem.

À família são impostos limites para entrar em questões próprias da escola, como no campo pedagógico. Mas o mesmo parece não acontecer com a escola em relação à sua entrada na família, pois aquela acredita estar autorizada a penetrar nos problemas domésticos e a lidar com eles, além de se considerar apta a estabelecer os parâmetros para a participação e o envolvimento da família.

Na tentativa de entender os fatores e razões que levam a escola e seus atores a atribuir importância fundamental a esta relação, segue um levantamento de pesquisas científicas realizadas sobre esta temática, dando prioridade aos trabalhos desenvolvidos no contexto brasileiro.

\section{Caminhos para estudar a relação família-escola}

\section{A visão da escola}

Uma das possibilidades para se estudar o tema da relação família-escola é conhecer as concepções de professores a respeito das famílias de seus alunos. Nesse sentido, pesquisa realizada com professores da educação infantil em uma escola do interior paulista sugere um desconhecimento, por parte dos professores, das características das famílias atendidas, ou uma imagem estereotipada das mesmas, uma vez que as descrições feitas estão carregadas de conotações negativas e preconceituosas (Tancredi \& Reali, 2001). Na visão de alguns professores o modelo de família que se configura é uma

104 família idealizada, que oferece suporte, aconchego e que tem funções diferentes para cada fase da vida (Oliveira, 2002).

A comunicação entre escola e família passa pela intermediação da criança, sendo esta comunicação aparentemente de mão única, por haver pouco espaço institucional para a manifestação das famílias. A ação das famílias é limitada e determinada de acordo com os interesses da escola. Assim,"num primeiro momento, defende-se uma participação ampla dos pais na escola, mas o que se verifica é uma participação que tem a ver com o fato de conhecer o trabalho da escola" (Oliveira, 2002, p.105).

Quanto ao tipo de interação estabelecido entre professores e famílias, "além de dar uma falsa aparência de intimidade, dá ao professor o controle do 'diálogo' mantido"(Tancredi \& Reali, 2001, p.12), já que as famílias são recebidas nos portões da escola, ou na porta da sala de aula, a partir da reinvidicação das próprias famílias, e pouco tempo é dedicado a esta interação.

As famílias não são vistas pelos professores como parceiras que têm objetivos comuns, apesar de estas se mostrarem conscientes do importante papel da escolarização na vida dos filhos, e de estarem dispostas a contribuir com a escola (Reali \& Tancredi, 2002). Na compreensão dos professores, o apoio dos pais no processo de ensino"se limita a reforçar aquilo que o professor realiza e pede às crianças, ao invés de sugerir que os pais poderiam se envolver mais com questões escolares de maneira mais participativa e recíproca" (Bhering, 2003, p.499).

Pesquisa com professores e diretores também apontou que o principal aspecto positivo ou vantagem da aproximação da família com a escola é o envolvimento dos pais na educação dos filhos. Este envolvimento diz respeito "a atitudes de co-responsabilidade e interesse dos pais com o processo de ensino-aprendizagem incluindo a participação ou colaboração em atividades, em eventos ou solicitações propostas pela escola" (Hernández, 1995, p. 59).

Entretanto, envolver a família na educação escolar pode representar uma ameaça para alguns professores, por se sentirem destituídos de sua competência e de seu papel de ensinar, apesar de que "a presença e participação dos pais na escola não pode e não deve siginificar uma desresponsabilização dos professores 
para com a aprendizagem dos alunos e do governo com o financiamento da educação" (Tancredi \& Reali, 2001, p.4).

Quanto às dificuldades encontradas no estabelecimento de relações harmoniosas, pode-se citar a forma que a escola adota, geralmente, para estabelecer contato com as famílias, a qual é unidirecional (parte da escola para a família) e motivada por situações de baixo rendimento escolar e de mau comportamento dos alunos (Bhering, 2003).

Outro membro da comunidade escolar que também está envolvido nas relações entre família e escola é o psicólogo escolar; portanto, ainda dentro da visão da escola sobre esta relação, tem-se as concepções dos psicólogos escolares. Nesta perspectiva, pesquisa realizada junto a psicólogas escolares na região de Campinas (SP) (Leal, 1998) apontou que a escola é que determina os tipos e a frequência das oportunidades de participação dos pais. A responsabilidade pelo sucesso ou pelo fracasso da relação foi atribuída, pelas psicólogas, a ambos os sistemas envolvidos, enquanto em relação à qualidade da relação família-escola, tenderam a responsabilizar mais a família que a escola pela insuficiência e obstáculos encontrados.

Para as psicólogas pesquisadas, promover a integração e orientar a família são maneiras importantes de mediar a relação família-escola, havendo uma "clara tendência dessas psicólogas em se envolver mais na orientação de pais e em reunião de pais, despendendo mais tempo e oferecendo com maior freqüência, o serviço de orientação" (Leal, 1998, p.96). Assim, a atuação dessas psicólogas restringe-se principalmente à orientação aos pais, levando à reflexão de que o psicólogo parece não estar investindo em inovações para possibilitar ou melhorar esta relação.

\section{A visão dos pais}

Outra possibilidade para se estudar o tema da relação família-escola é conhecer a concepção dos pais sobre a relação entre família e escola. Os estudos de Bhering e Siraj-Blatchford (1999) e Bhering (2003) identificaram que, para os pais, o envolvimento deve ser de responsabilidade e iniciativa da escola, enquanto o papel deles seria complementar às metas educacionais da escola.
Para os pais, o envolvimento refere-se a uma forma de participar intensamente de atividades relacionadas ao ensino e à aprendizagem escolar, tanto em casa quanto na escola; diz respeito a diversos procedimentos adotados pelos pais para auxiliar na aprendizagem dos filhos (deveres de casa, leitura de livros, jogos que estimulam o desenvolvimento cognitivo) e à participação ativa na escola (na sala de aula, biblioteca, excursões). A ajuda ou colaboração refere-se à prestação de serviços como, por exemplo, em eventos sociais, feiras, festivais, excursões e aquisição de materiais e equipamentos para a escola.

Na visão das famílias as interações estabelecidas com a escola ocorrem nos horários de saída, nas reuniões de pais convocadas pela escola ou em datas comemorativas, o que ilustra um relacionamento superficial e limitado a situações "formais", como as reuniões bimestrais e as comemorações, ambas organizadas pela escola (Reali \&Tancredi, 2002).

Quanto à função de cada um (pais e professores), embora apresentem preocupações comuns, como o bom desempenho escolar das crianças, pais e professores acreditam ter tarefas diferentes e mostram-se relutantes em fazer aquilo que consideram ser tarefa do outro. Para os pais, os professores deveriam manter a educação escolar como sua responsabildiade, enquanto aos pais caberia assegurar que as crianças estivessem prontas para a educação escolar (Bhering, 2003).

Ainda quanto à opinião dos pais, o Ministério da Educação (MEC), por meio do Instituto Nacional de Estudos e Pesquisas Educacionais Anísio Teixeira (INEP), realizou um estudo de âmbito nacional sobre a relação família, escola e educação (Brasil, 2005). No âmbito nacional, as reuniões de pais e professores são os eventos que mais mobilizam os responsáveis, sendo que um chamado imprevisto para o comparecimento à escola desperta fortes apreensões na família, pois surge, de imediato, a ideia de que a convocação está relacionada a problemas disciplinares de alguma gravidade, ou de baixo rendimento ou, ainda, de alguma deficiência, tratando-se, sempre, de um fato já ocorrido e que será apenas comunicado aos pais.

\section{A visão dos alunos}

Comumente, as pesquisas realizadas sobre a temática da relação família-escola privilegiam as opi- 
niões dos professores e dos pais. Todavia, duas pesquisas recentes focalizam a opinião dos alunos sobre a temática da relação família-escola.

Um estudo realizado junto a estudantes do ensino médio de uma escola particular em Curitiba (PR) investigou como os alunos das três séries do ensino médio $\left(1^{\circ}, 2^{\circ}\right.$ e $3^{\circ}$ anos) veem a relação da escola com a família. De acordo com os resultados, identificou-se que os alunos das três séries percebem a relação família-escola de uma maneira muito negativa. Para os alunos, a cobrança quanto ao rendimento escolaré uma questão bastante presente; a relação familiar baseada no diálogo mostra-se comprometida devido à falta de tempo dos pais e à não liberdade que os alunos têm para tratar de suas intimidades com os pais (Cardoso, 2003). A convocação dos pais ao colégio em situações que se referem apenas às notas ou ao comportamento deixa os alunos "revoltados" por não terem sido consultados e por não haver a mesma ação quando se trata de elogios.

Em pesquisa realizada no Distrito Federal (DF) sobre as relações família-escola, também participaram alunos de 1a, $5^{a}$ e $8^{a}$ séries do ensino fundamental de escolas públicas do DF. Os resultados obtidos na pesquisa apontam que, na visão dos alunos, há paulatinamente um decréscimo da participação dos pais nas atividades programadas pela escola, à medida que o aluno avança na série. "Os pais das séries iniciais estão mais presentes nas atividades programadas pela escola, havendo uma diminuição da sua participação quando o aluno avança na série, de modo que, na 8 a série, a sua participação é bastante limitada" (Polonia, 2005, p.155).

De acordo com os alunos, a presença nas reuniões e conselhos de classe é a atividade mais frequente com envolvimento dos pais, superando a participação nos eventos socioculturais, em que se nota um decréscimo na participação, especialmente para os alunos de $5^{a}$ e $8^{a}$ séries (Polonia, 2005).

Entre as ações apontadas pelos alunos que poderiam ser desencadeadas pelos pais e pela escola para melhorar as condições da escola, destacam-se aquelas em que eles se posicionam como possíveis mediadores da relação família-escola, ou seja, aquelas ações que podem ser realizadas pelos próprios alunos, como estimular a participação dos pais e intermediar a 106 comunicação entre a escola e os pais. Polonia (2005)

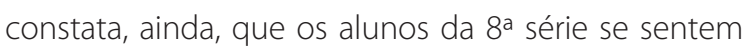
mais responsáveis pela intermediação (entregar bilhetes, avisos e informes), enquanto os alunos da 1a série se sentem mais responsáveis pelo estímulo à participação (contar mais sobre as atividades desenvolvidas na escola, solicitar a participação dos pais etc.).

Este último dado sinaliza para o importante papel que os próprios alunos podem assumir diante das relações entre suas famílias e a escola, pois, geralmente, ao investigar os processos de comunicação entre a família e a escola, suas influências, intersecções e interações, as pesquisas focalizam especialmente o papel dos adultos nesta interrelação.

A partir dos relatos de pesquisas que, em seu desenho metodológico, investigaram a visão dos diferentes segmentos de participantes envolvidos na relação família-escola, pode-se observar o quanto esta relação se apresenta de maneira diferente para cada um deles. Se, por um lado, pais e professores compartilham a preocupação com o desempenho escolar dos filhos e alunos, de outro, não compartilham as mesmas ideias sobre como cada um desses segmentos pode contribuir para o sucesso dos filhos. Além disso, se para os pais e para a escola o rendimento escolar é um aspecto que motiva a relação família-escola, para os alunos, a cobrança quanto ao rendimento escolar é uma questão bastante presente e negativa.

A partir desta breve descrição de pesquisas científicas, entende-se que pontos importantes para a compreensão atual da relação família-escola foram sinalizados, além de outros que apontam para aspectos que precisam ser modificados em prol do sucesso desta relação.

\section{Considerações Finais}

Entre as instituições que se responsabilizam pelo processo educativo do ser humano tem-se a família e a escola. A literatura contemporânea indica que a família é caracterizada por, pelo menos, uma díade ou par e pela presença de intimidade na relação, e tem como função orientar os sujeitos no desenvolvimento e aquisição de comportamentos aceitos socialmente. A escola, por sua vez, tem como função a socialização do saber sistematizado historicamente. 
Escola e família são instituições diferentes e que apresentam objetivos distintos; todavia, compartilham a importante tarefa de preparar crianças e adolescentes para a inserção na sociedade, a qual deve ter uma característica crítica, participativa e produtiva.

Analisando a história da relação que se estabeleceu entre escola e família ao longo do tempo, identifica-se que em certos momentos essa relação foi caracterizada em função de determinantes sociais e, em outros, em função de aspectos psicológicos da família e do próproio sujeito. Diz-se, de forma geral, que esta relação sempre esteve marcada por movimentos de culpabilização de uma das partes envolvidas, pela ausência de responsabilização compartilhada de todos os envolvidos e pela forte ênfase em situações-problema que ocorrem no contexto escolar.

A despeito das situações-problema que permeiam a relação família-escola, acredita-se que a iniciativa de construir uma relação harmoniosa entre as duas instituiç̧ões deve ser de responsabilidade da escola e de seus profissionais, que têm uma formação específica. Contudo, os parâmetros para esta relação não devem se basear, apenas, na função de orientar os pais sobre como ensinar seus filhos, como tem preconizado a escola.

Diante destes aspectos, considera-se que a relação entre a família e a escola tem-se caracterizado por ser um fenômeno pouco harmonioso e satisfatório, uma vez que as expectativas de cada instituição ou de cada ator envolvido não são atendidas e se mostram pouco favoráveis ao crescimento e desenvolvimento dos alunos, os quais se aborrecem com a relação em vez de tê-la como fonte de apoio e colaboração.

A relação entre família e escola se estabeleceu, e ainda se mantém, a partir de situações vinculadas a algum tipo de problema e, desta forma, pouco contribui para que as duas instituições possam construir uma parceria baseada em fatores positivos e gratificantes relacionados ao aprendizado, desenvolvimento e sucesso dos alunos.

Em virtude desta marca no entrelaçamento entre a família e a escola, as posturas relacionadas a esta relação caracterizam-se por ser defensivas e acusativas, como se cada um buscasse se justificar e encontrar razões para a desarmonia que caracteriza tal relação.
Diante disso, um importante desafio surge para os pesquisadores, estudiosos e profissionais da educação: o de modificar a relação família-escola no sentido de que ela possa ser associada a eventos positivos e agradáveis e que, efetivamente, contribua com os processos de socialização, aprendizagem e desenvolvimento.

Para que este desafio seja superado é necessário o desenvolvimento de pesquisas que invistam no conhecimento da relação família-escola; por esta razão, defende-se a importância de novas investigações que procurem conhecer as práticas que a norteiam e a atuação dos profissionais que nela estão envolvidos, a fim de oportunizar a reflexão e implementação de novas possibilidades de intervenção que promovam mudanças significativas na relação família-escola.

\section{Referências}

Bhering, E. (2003). Percepções de pais e professores sobre o envolvimento dos pais na educação infantil e ensino fundamental. Contrapontos, 3 (3), 483-510.

Bhering, E., \& Siraj-Blatchford, I. (1999). A relação escola-pais: um modelo de trocas e colaboração. Cadernos de Pesquisa, 106, 191-216.

Bock, A. M. B., Furtado, O., \&Teixeira, M. L. T. (1999). Psicologias: uma introdução ao estudo da psicologia. São Paulo: Saraiva.

Brasil. Ministério da Educação. Instituto Nacional de Estudos e Pesquisas Educacionais. (2005). Pesquisa nacional qualidade da educação: a escola pública na opinião dos pais: resumo técnico executivo. Brasília: Ministério da Educação.

Brasil. Senado Federal. (1988). Constituição da República Federativa do Brasil. Brasília: Senado Federal.

Caetano, L. M. (2004). Relação escola e família: uma proposta de parceria. Dialógica, 1 (1), 51-60.

Cardoso, R. L. de C. (2003). A relação escola-família na formação do adolescente-aluno do Ensino Médio do Colégio Medianeira. Dissertação de mestrado não-publicada, Universidade Tuiuti do Paraná, Curitiba.

Guzzo, R. S. L. (1990). A família e a educação: uma perspectiva da integração família-escola. Estudos de Psicologia (Campinas), 7 (1), 134-139.

Hernández, A. M. S. (1995). A relação escola e família na opinão de seus agentes. Dissertação de mestrado não-publicada, Pontifícia Universidade Católica de Campinas.

Leal, G. C. (1998). Relação entre família e escola: o psicólogo escolar como mediador. Dissertação de mestrado não-publicada, Pontifícia Universidade Católica de Campinas.

Marques, R. (1999). A escola e os pais, como colaborar? Lisboa: Texto Editora. 
Oliveira, L. C. F. (2002). Escola e família numa rede de (des)encontros: um estudo das representações de pais e professores. São Paulo: Cabral Editora.

Petzold, M. (1996). The psychological definition of the family. In M. Cusinato (Org.), Research on family resources and needs across the world (pp.25-44). Milano-Itália: LEDEdizioni Universitarie.

Polonia, A.C. (2005). As relações escola-família: o que diretores, professores, pais e alunos pensam? Tese de doutorado não-publicada, Universidade de Brasília.

Polonia, A. C., \& Dessen, M. A. (2005). Em busca de uma compreensão das relações entre família e escola. Psicologia Escolar e Educacional, 9 (2), 303-312.

Reali, A. M. M. R., \& Tancredi, R. M. S. P. (2002). Interação escola-famílias: concepções de professores e práticas pedagógicas. In M. G. N. Mizukami \& A. M. M. R. Reali (Orgs.), Formação de professores, práticas pedagógicas e escola (pp.74-98). São Carlos: EdUFSCar.

Reali, A. M. M. R., \& Tancredi, R. M. S. P. (2005). A importância do que se aprende na escola: a parceria escola-famílias em perspectiva. Paidéia, 15 (31), 239-247.

Saviani, D. (2005). Pedagogia histórico-crítica: primeiras aproximações. Campinas: Autores Associados.
Stratton, P. (2003). Contemporary families as contexts for development. In J. Valsiner \& K. Connolly (Orgs.), Handbook of developmental psychology (pp.333-357). London: Sage.

Tancredi, R. M. S. P., \& Reali, A. M. M. R. (2001). Visões de professores sobre seus alunos: um estudo na área da educação infantil. Trabalho apresentado na 24a Reunião Anual da ANPEd. (pp.1-16). Caxambu. Recuperedo em abril, 2006, disponível em www.anped.org.br

Trost, J. (1995). O processo de formação da família. In J. Gomes-Pedro \& M. F. Patricio (Orgs.), Bebé XXI: criança e família na viragem do século (pp.55-67). Lisboa: Fundação Calouste Gulbenkian.

Turner, L. H., \& West, R. (1998). Providing a definition. In L. H. Turner \& R. West (Orgs.), Perspectives on family communication (pp.1-35). Mountain View, CA: Mayfield Publishing Company.

Recebido em: 14/4/2008

Versão final reapresentada em: 18/12/2008

Aprovado em: 5/3/2009

108 